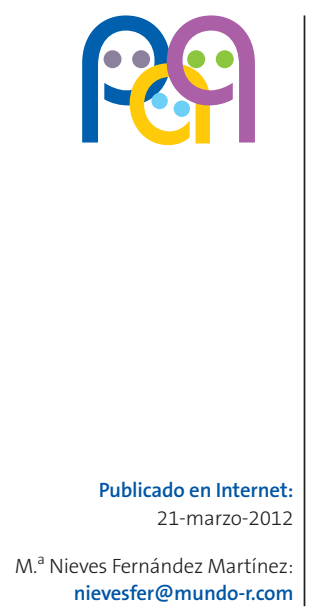

\title{
Nota clínicas
}

\section{Piomiosistis como complicación de la varicela. A propósito de un caso}

\author{
M. N. Fernández Martínez ${ }^{a}$, J. Ramallo Hermo a , M. S. Cameán Hermo ${ }^{b}$

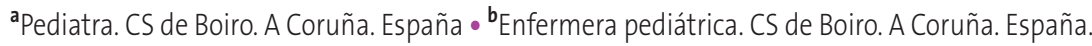

\begin{tabular}{|c|c|c|}
\hline \multirow[b]{3}{*}{$\begin{array}{r}\text { Palabras clave: } \\
\text { • Varicela } \\
\text { - Complicaciones } \\
\text { - Piomiositis }\end{array}$} & \multirow{3}{*}{ 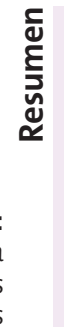 } & \multirow{2}{*}{$\begin{array}{l}\text { La varicela es la enfermedad exantemática más frecuente en la infancia. Generalmente es benigna y } \\
\text { autolimitada. Están descritas complicaciones que requieren tratamiento hospitalario y que están asocia- } \\
\text { das a una alta morbimortalidad. } \\
\text { La piomiositis o infección aguda del músculo estriado es, aunque infrecuente, una de las posibles com- } \\
\text { plicaciones musculoesqueléticas de la varicela. }\end{array}$} \\
\hline & & \\
\hline & & $\begin{array}{l}\text { Presentamos el caso de un niño que durante la convalecencia de dicha enfermedad presentó como } \\
\text { complicación una celulitis del miembro inferior y, posteriormente, una piomiositis del músculo gastroc- } \\
\text { nemio. }\end{array}$ \\
\hline \multicolumn{3}{|r|}{ Pyomiositis as a complication of varicella. A case report } \\
\hline \multirow{2}{*}{\multicolumn{2}{|c|}{ 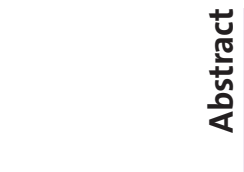 }} & $\begin{array}{l}\text { Varicella is the most common exanthematic disease in childhood. It is usually benign and self-limited. } \\
\text { Some complications that require hospital treatment and are associated with high morbidity and mortal- } \\
\text { ity are reported. }\end{array}$ \\
\hline & & $\begin{array}{l}\text { Pyomyositis or acute infection of the striated muscle is, although rare, one of the musculoskeletal pos- } \\
\text { sible complications of varicella. }\end{array}$ \\
\hline $\begin{array}{r}\text { Key words: } \\
\text { - Varicella } \\
\text { - Complications } \\
\text { - Pyomyositis }\end{array}$ & & $\begin{array}{l}\text { We present the case of a child that, while convalescing from that disease, presented lower limb cellu- } \\
\text { lites, and later a pyomyositis of the gastrocnemius muscle. }\end{array}$ \\
\hline
\end{tabular}

\section{CASO CLÍNICO}

Niño de dos años y seis meses de edad, previamente sano y correctamente vacunado, excepto de varicela.

Tuvo escarlatina seis días antes de la aparición del exantema. Al quinto día persiste fiebre alta y presenta edema en el pie y el tobillo izquierdos. Es diagnosticado de celulitis de tobillo y tratado ambulatoriamente con amoxicilina-clavulánico oral en dosis de 80 mg/kg/día (de amoxicilina). A las 48 horas aumenta la tumefacción, por lo que se decide su ingreso.

En la exploración presenta buen estado general, con múltiples lesiones de varicela de predominio pustuloso, dolor, tumefacción, edema importante en el pie y el tobillo izquierdos y placa eritematosa en la planta del pie. No realiza deambulación autónoma. El resto de la exploración física está dentro de la normalidad.

El control analítico muestra 13600 leucocitos/ $\mathrm{mm}^{3}$ (68,3\% neutrófilos); hemoglobina, 10,7 g/dl; 
hematocrito, 31,1\%; plaquetas, $374000 / \mathrm{mm}^{3}$, y velocidad de sedimentación globular (VSG), 116. Hemocultivo negativo.

Se trata con amoxicilina/clavulánico intravenoso (IV), pero al cuarto día presenta un empeoramiento de la tumefacción. Se le realiza una radiografía del miembro inferior que muestra un aumento de partes blandas, y una ecografía que muestra un músculo gemelo interno con hipoecogenicidad y tumefacción con pérdida de patrón fibroadiposo, que refleja edema e infiltración de tejido graso compatible con piomiositis. No hay constancia de absceso susceptible de drenaje (Fig. 1).

Se instaura tratamiento antibiótico con cefotaxima y cloxacilina, pero al ser la evolución clínica, analítica y ecográfica desfavorable, se decide un cambio de pauta por clindamicina y vancomicina IV con posterior disminución de la VSG y ecografía sin alteraciones significativas. Al alta realizaba deambulación autónoma y no presentaba secuelas funcionales.

\section{DISCUSIÓN}

La varicela es la enfermedad exantemática más frecuente en la infancia ${ }^{1}$. Es una infección común en países que no han incorporado la vacuna en sus calendarios vacunales ${ }^{2}$.

Generalmente es benigna en niños inmunocompetentes y no necesita tratamiento. En un número no despreciable de niños, la infección es relativamente grave, presentando complicaciones importantes ${ }^{1,2}$.

En EE. UU., antes de 1995, la varicela afectaba a unos cuatro millones de personas anualmente, de las cuales un 0,3\% requería hospitalización y 100 $(0,0025 \%)$ morían por complicaciones ${ }^{2}$. Aunque la letalidad atribuible a la varicela es extremadamente baja, el riesgo de muerte por sus complicaciones no es despreciable.

En el estudio realizado por Sáez-Llorens et al. ${ }^{2}$, falleció el 2,5\% de los niños con varicela complicada. En dicho estudio incluyeron un total de 513 niños diagnosticados de varicela complicada y demostraron que los costes relacionados con los cuidados de Enfermería y médicos, los días de estancia hospitalaria, la administración de medicamentos y las pruebas complementarias eran considerables.

Las causas más frecuentes de hospitalización en niños inmunocompetentes con varicela incluyen las infecciones de la piel y el tejido subcutáneo, la neumonía y las alteraciones neurológicas, aunque hay un predominio abrumador de las infecciones cutáneas $^{2}$. Dichas complicaciones se deben a que la varicela provoca cierta inmunosupresión y, por las características de sus lesiones, disrupción de la barrera defensiva de la piel ${ }^{3}$.

Las infecciones bacterianas varían desde impétigo por Staphylococcus aureus o Streptococcus pyogenes hasta enfermedades invasivas con diseminación hematógena, como bacteriemia, sepsis y focos a distancia ${ }^{1,3}$.

La piomiositis, también conocida como miositis infecciosa, es la infección bacteriana del músculo. Los músculos que se afectan con mayor frecuencia son los músculos largos de los miembros y el tron$\mathrm{CO}^{4}$. Puede clasificarse en primaria y secundaria. De acuerdo con Gordon ${ }^{5}$, se define un absceso como primario cuando no existe un foco de infección obvio ni conocido, y secundario cuando ocurre por propagación o extensión directa de un proceso infeccioso como apendicitis, osteomielitis, diverticulitis, trauma penetrante, etc.

La etiopatogenia de la piomiositis aún no es bien conocida. En niños sanos, el antecedente traumático previo, en ocasiones leve, es el factor encontrado con mayor frecuencia ${ }^{6,7}$. Como factores facilitadores se mencionan la malnutrición, las enfermedades de base, el factor climático (ambiente tropical) y las lesiones cutáneas por varicela asociadas a Streptococcus pyogenes ${ }^{7,8}$. En un estudio realizado por Coria Lorenzo et al., en el que revisaban la experiencia clínica acerca de niños con piomiosistis hospitalizados, comprobaron que la varicela había sido el factor más frecuente que precedía a la enfermedad ${ }^{8}$. El $33-40 \%$ de los caso de piomiosistis se produce en niños y más frecuentemente en varones ${ }^{7,8}$. 


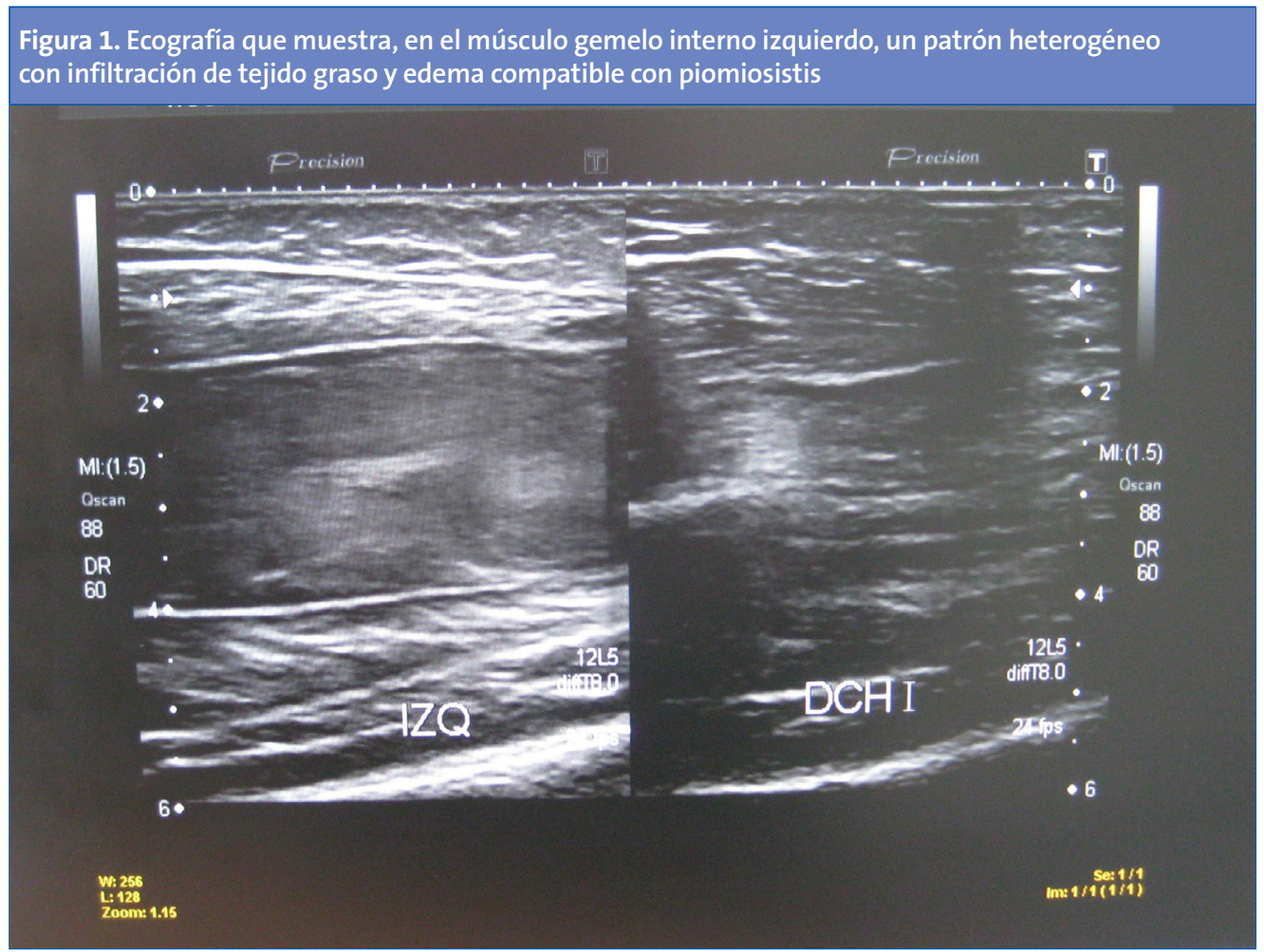

Los síntomas incluyen fiebre alta, calambres musculares y dolor, seguidos de signos inflamatorios locales y limitación a la movilidad del músculo infectado ${ }^{7}$.

El diagnóstico precoz requiere un alto índice de sospecha, dado que es un proceso poco frecuente, cuyos síntomas son muy inespecíficos y variados ${ }^{7}$.

Desde el punto de vista microbiológico, el hemocultivo es positivo solo en una tercera parte, aunque el cultivo del absceso aísla el microorganismo en la mayoría de los casos. El agente aislado con mayor frecuencia es el Staphylococcus aureus, seguido del Streptococcus pyogenes, que suele ser el agente causal de las piomiosistis secundarias a varicela $a^{6,7}$.

Los exámenes de laboratorio son muy inespecíficos, con leucocitosis moderada y desviación a la izquierda, VSG y proteína $C$ reactiva elevadas y sin alteraciones de las enzimas musculares.

Debido a la progresión tan insidiosa de los síntomas y lo difícil que puede ser el diagnóstico en los primeros estadíos, es necesario hacer uso de los estudios de imagen. La ecografía, por disponibilidad y coste, sería la prueba inicial que debería realizarse. Cuando la ecografía no es del todo resolutiva, debemos utilizar la tomografía computarizada (TC), pues tiene gran valor diagnóstico y terapéutico como guía para punciónaspiración con aguja fina y drenaje del absceso si lo hubiera ${ }^{6,7}$. La prueba más sensible es la resonancia magnética aunque su disponibilidad es menor ${ }^{7}$.

En cuanto al tratamiento de la enfermedad, requiere una terapia antibiótica prolongada. Se recomienda una combinación con clindamicina, por su gran actividad frente a los microorganismos citados. La duración de la antibioticoterapia oscila entre cuatro y seis semanas, y debe ir asociada a la aspiración de material purulento y a la colocación de drenaje guiado mediante ecografía o TC, en caso de que hubiera un absceso susceptible de drenaje. 


\section{Conclusiones}

La varicela es una infección que puede asociarse a un número importante de complicaciones y a una letalidad nada despreciable.

La piomiosistis, una de las posibles complicaciones de la varicela, es una entidad infrecuente en países templados como el nuestro, y su diagnóstico inicial resulta muy dificil y requiere un alto índice de sospecha. Deberíamos tenerla presente ante todo niño con antecedentes de varicela y que presenta fiebre y signos inflamatorios locales en cualquier extremidad.

\section{BIBLIOGRAFÍA}

1. Larcamon JE, Juanco G, Álvarez LA, Pebe FV. Absceso del psoas como complicación de varicela. Arch Argent Pediatr. 2010;108:86-8.

2. Sáez-Llorens X, de Suman O, de Morós D, Rubio MP. Complicaciones y costos asociados a la varicela en niños inmunocompetentes. Rev Panam Salud Pública. 2002;12:111-5.

3. Darmstadt GL. Infecciones cutáneas bacterianas. En: Berman R, Kliegman R, Jonson H (eds.). Nelson. Tratado de Pediatría, 16. ed. México: Editorial McGrawHill-Interamericana; 2001. p. 1064-72.

4. Saavedra Lozano J, Santos Sebastián M, González F, Hernández-Sampelayo Matos T, Navarro Gómez ML.
El tratamiento se basa en antibióticos y drenaje quirúrgico cuando esté indicado.

\section{CONFLICTO DE INTERESES}

Los autores declaran no presentar conflictos de intereses en relación con la preparación y publicación de este artículo.

\section{ABREVIATURAS}

IV: intravenoso • TC: tomografía computarizada • VSG: velocidad de sedimentación globular.

Infecciones bacterianas de la piel y tejidos blandos. En: AEP. Protocolos de Infectología; 2009. p. 145-60.

5. Gordon JE. Chickenpox: An Epidemiological review. Am J Med Sci. 1962;244:362.

6. Moreno LA, Montoya RD, Bolaños LL. Piomiositis: Presentación de un caso. Rev Colomb Radiolog. 2007;18:2143-7.

7. Castells Viella L, Uriz Urzainqui S. Piomiositis estreptocócica como complicación infrecuente de la varicela. An Pediatr (Barc). 2004;60:595-7.

8. Coria Lorenzo JJ, Gutiérrez Moreno R, Rosales Uribe E, Juárez Escobar M. Siete años de experiencia en niños con miosistis en un hospital de niños. Rev Mex Pediatr. 2004;71:278. 